\title{
The effectiveness of various iron-supplementation regimens in improving the Fe status of anaemic rats
}

\author{
BY A. J. A. WRIGHT AND SUSAN SOUTHON \\ AFRC Institute of Food Research, Colney Lane, Norwich NR4 $7 U A$
}

(Received 28 September 1989 - Accepted 13 December 1989)

\begin{abstract}
Less frequent iron supplementation may be equally as beneficial to Fe-deficient subjects as routine daily supplementation because of the short-term suppressive effect of oral dosing with large amounts of Fe on subsequent $\mathrm{Fe}$ absorption. In the present study, the possibility that the administration of an $\mathrm{Fe}$ supplement every 2 nd or 3rd day may be as effective in improving Fe status as a daily supplement was investigated in anaemic rats. Anaemic rats were given a $4 \mathrm{mg}$ Fe supplement every day, on alternate days or every 3rd day, as a single dose with a midday meal or as a multiple dose with a morning, midday and evening meal. A low-Fe diet (13 mg/kg) was given at all other times. After $7 \mathrm{~d}$, erythrocyte count, packed cell volume, mean cell volume, haemoglobin concentration and total liver Fe were measured and compared with those of meal-fed rats which had not been given any supplemental Fe. Rats which received a supplement every 3rd day, a total supplement of $12 \mathrm{mg}$, had a similar Fe status to those receiving a daily supplement, a total supplement of $28 \mathrm{mg}$. Administration of the supplement as a multiple, rather than as a single dose did not improve recovery from the Fe deficiency. It is suggested that less frequent supplementation with a smaller total amount of $F e$, should be considered in human subjects. Such a regimen would minimize unpleasant side-effects of oral Fe therapy, decrease the risk of adverse effects of $\mathrm{Fe}$ on the absorption of other essential minerals and substantially cut the cost of supplementation programmes.
\end{abstract}

Iron-supplementation regimen: Iron status: Anaemia: Rat

There are a number of studies in the literature demonstrating suppression of iron absorption in non-anaemic laboratory animals and human subjects for a least $24 \mathrm{~h}$ after the consumption of a high-Fe meal or Fe supplement (Solomons et al. 1983; Fairweather-Tait et al. 1985; Fairweather-Tait \& Minski, 1986; O'Neil-Cutting \& Crosby, 1987), which appears to be the result of a marked local effect of exposure to Fe on the regulatory role of the intestinal epithethial cells; principally perhaps in the controlled suppression of mucosal uptake (Wright et al. 1989). It is likely, therefore, that a substantial proportion of $\mathrm{Fe}$, given as a daily supplement to pregnant women and to subjects with symptoms of $\mathrm{Fe}$ deficiency, remains unabsorbed. It has been suggested that less frequent supplementation may be equally as beneficial to the subject as routine daily supplementation (FairweatherTait, 1986), whilst reducing both the unpleasant side-effects, such as nausea and epigastric pain, and the cost of supplementation. However, little is known about the relative effectiveness of various supplementation regimens in improving the $\mathrm{Fe}$ status of anaemic subjects.

In the present study, the possibility that smaller amounts of supplemental Fe, administered every 2 nd or 3 rd day, may be just as beneficial as routine daily supplementation was investigated in the rat. In addition, the possibility that administration of a supplement in several smaller doses, taken throughout the day, may be a more efficient means of Fe therapy than giving a -ingle large dose was considered. Though the absolute amount of $\mathrm{Fe}$ absorbed always i.. reases with increasing dose, the proportion of $\mathrm{Fe}$ absorbed from small doses has becn shown to be greater than that from larger doses 
Table 1. Composition ( $\mathrm{g} / \mathrm{kg}$ ) of low-iron $(13 \mathrm{mg} \mathrm{Fe} / \mathrm{kg})$, medium- $\mathrm{Fe}(460 \mathrm{mg} \mathrm{Fe} / \mathrm{kg})$ and high-Fe $(1350 \mathrm{mg} \mathrm{Fe} / \mathrm{kg})$ diets

\begin{tabular}{lll}
\hline$\ldots \ldots$ & 309 \\
& Maize starch & 309 \\
& Sucrose & 200 \\
& Casein & 40 \\
& Cellulose* & 40 \\
& Mineral mix & 20 \\
& Vitamin mix & 2 \\
& DL-methionine & 80 \\
& Maize oil & \\
& \\
&
\end{tabular}

* Solka Floc ${ }^{\text {s }}$; Johnson, Jurgensen \& Wettre Ltd, London.

$\dagger$ Mineral mix (g/kg diet): $\mathrm{CaHPO}_{4} 13 \cdot 0, \mathrm{CaCO}_{3} 8 \cdot 2, \mathrm{KCl} 7 \cdot 03, \mathrm{Na}_{2} \mathrm{HPO}_{4} 7 \cdot 4, \mathrm{MgSO}_{4} \cdot \mathrm{H}_{2} \mathrm{O} 4 \cdot 0, \mathrm{MnSO}_{4} \cdot \mathrm{H}_{2} \mathrm{O}$ $0 \cdot 18, \mathrm{ZnCO}_{3} 0.025, \mathrm{CuSO}_{4} .5 \mathrm{H}_{2} \mathrm{O} 0.023, \mathrm{KIO}_{3} 0 \cdot 001, \mathrm{FeSO}_{4} \cdot 7 \mathrm{H}_{2} \mathrm{O}$; low-Fe 0.025 , medium-Fe $2 \cdot 244$, high-Fe 6.664 .

$\$$ Vitamin $\operatorname{mix}(\mathrm{mg} / \mathrm{kg}$ diet): nicotinic acid 60, cyanocobalamin (in mannitol) 50, calcium-D-pantothenate 40 , thiamin hydrochloride 10 , riboflavin 10 , pyridoxine 10 , pteroylmonoglutamic acid 10 , D-biotin 1 , vitamin $K_{1}$ (in lactose) 2, Rovimix E-50 150 (containing $75 \mathrm{mg}$ as DL- $\alpha$-tocopheryl acetate; Roche), Rovimix A-500 25 (containing $3.75 \mathrm{mg}$ as retinol; Roche), Rovimix $\mathrm{D}_{3}-50015$ (containing $188 \mu \mathrm{g}$ as cholecalciferol; Roche), choline bitartrate 1800 , starch (bulking agent) 17817.

(Bothwell et al. 1979), and reducing the amount of Fe consumed at any one time might diminish the sensitive mucosal cell feed-back inhibition of subsequent $\mathrm{Fe}$ absorption (Fairweather-Tait \& Wright, 1984).

Anaemic rats were given an Fe supplement every day, on alternate days or every 3rd day, over a period of $7 \mathrm{~d}$. The same amount of supplemental Fe was also administered either as a single dose in a midday meal, or as a multiple dose in morning, midday and evening meals. At the end of the experimental period the Fe status of supplemented rats was compared with that of a control group of anaemic animals which did not receive any supplemental Fe.

\section{MATERIALS AND METHODS}

Ninety-four immature, male, Wistar rats, weighing approximately $50 \mathrm{~g}$, were caged individually in polypropylene cages with stainless-steel gridded tops and bottoms in a room at $21^{\circ}$ having a $12 \mathrm{~h}$ light $-12 \mathrm{~h}$ dark cycle. All rats were fed on a powdered semi-synthetic diet containing $13 \mathrm{mg} \mathrm{Fe} / \mathrm{kg}$ (designated the low-Fe diet) for $14 \mathrm{~d}$; ad lib. for the first 10 $\mathrm{d}$ and meal-fed on three $3 \mathrm{~g}$ meals $/ \mathrm{d}$, at $08.30,13.00$ and 17.00 hours, for $4 \mathrm{~d}$.

Distilled water was always available. The composition of the low-Fe diet is shown in Table 1 . At the end of this $14 \mathrm{~d}$ period, ten rats were killed by an intraperitoneal injection of sodium pentabarbital ( $1 \mathrm{ml}, 160 \mathrm{mg} / \mathrm{ml}$, Euthatal; May \& Baker, Dagenham, Essex), exsanguinated by cardiac puncture and the livers removed. Erythrocyte count (RBC), packed cell volume (PCV), mean cell volume (MCV) and haemoglobin ( $\mathrm{Hb}$ ) concentration were determined promptly on samples of heparinized blood using a semi-automated Coulter Counter (model CBC-5; Coulter Electronics, Luton). Livers were rinsed in cold isotonic saline ( $9 \mathrm{~g}$ sodium chloride/1), freeze-dried, weighed, ground to an homogenous powder, dry-ashed at $480^{\circ}$ and taken up into hydrochloric acid for $\mathrm{Fe}$ analysis by atomic absorption spectroscopy (PU 9000; Pye Unicam, Cambridge).

The remaining eighty-four rats were randomly allocated to one of seven groups and given three $3 \mathrm{~g}$ meals $/ \mathrm{d}$, at $08.30,13.00$ and 17.00 hours, for a further $7 \mathrm{~d}$. A $4 \mathrm{mg}$ Fe supplement was given as a single supplement with the midday meal every day (group 2), on alternate days (group 3) or every 3rd day (group 4), or as a multiple supplement given in each of the three meals every day (group 5), on alternate days (group 6) or every 3rd day (group 7). The 
Table 2. Supplementation regimens for rats

(Each rat was given three $3 \mathrm{~g}$ meals of semi-synthetic diet/d at $08.30(\mathrm{~A}), 13.00$ (B) and 17.00 (C) hours containing $13(\mathrm{~L}), 460(\mathrm{M})$ or $1350(\mathrm{H}) \mathrm{mg} \mathrm{Fe} / \mathrm{kg}$ for $\left.7 \mathrm{~d}^{*}\right)$

\begin{tabular}{|c|c|c|c|c|c|c|c|c|}
\hline $\begin{array}{l}\text { Day of } \\
\text { experiment... } \\
\text { Meal... } \\
\text { Group }\end{array}$ & 1 & $\begin{array}{l}2 \\
\mathrm{ABC}\end{array}$ & $\begin{array}{l}3 \\
\mathrm{ABC}\end{array}$ & $\begin{array}{l}4 \\
\mathrm{ABC}\end{array}$ & $\begin{array}{l}5 \\
\mathrm{ABC}\end{array}$ & $\begin{array}{l}6 \\
\mathrm{ABC}\end{array}$ & $\begin{array}{l}7 \\
\mathrm{ABC}\end{array}$ & $\begin{array}{c}\text { Total Fe } \\
\text { supplement } \\
\text { over } 7 \mathrm{~d}(\mathrm{mg})\end{array}$ \\
\hline 1 & LLL & LLL & LLL & LLL & LLL & LLL & LLL & - \\
\hline $2 \dagger$ & LHL & LHL & LHL & LHL & LHL & LHL & LHL & 28 \\
\hline $3 \dagger$ & LHL & LLL & LHL & LLL & LHL & LLL & LHL & 16 \\
\hline $4 \dagger$ & LHL & LLL & LLL & LHL & LLL & LLL & LHL & 12 \\
\hline $5 \ddagger$ & MMM & MMM & MMM & MMM & MMM & MMM & MMM & 28 \\
\hline 64 & MMM & LLL & MMM & LLL & MMM & LLL & MMM & 16 \\
\hline $7 \ddagger$ & MMM & LLL & LLL & MMM & LLL & LLL & MMM & 12 \\
\hline
\end{tabular}

* For details of diets, see pp. 580-581.

$\dagger$ Supplement was $4 \mathrm{mg} \mathrm{Fe}$ as ferrous sulphate incorporated into a single meal where indicated $(\mathrm{H})$.

$\ddagger$ Supplement was $1.33 \mathrm{mg} \mathrm{Fe}$ as ferrous sulphate incorporated into each of the three daily meals where indicated (M).

low-Fe diet was given at all other times. Group 1 were not supplemented and continued on the low-Fe diet throughout the experiment. The supplemented diet given to groups 2-4 (single supplement) and groups 5-7 (multiple supplement) contained 1340 and $460 \mathrm{mg}$ $\mathrm{Fe} / \mathrm{kg}$ respectively. Thus, on the days on which the supplement was given each rat received a total daily supplement of $4 \mathrm{mg}$ Fe. The composition of these diets is shown in Table 1 and the supplementation regimens in Table 2.

The amount of supplemental Fe given to the rats in the present study was chosen with reference to the possible increase in the daily intake of human subjects receiving commonly prescribed Fe supplements $(20-100 \mathrm{mg} / \mathrm{d})$, which would provide approximately two to ten times more Fe than the daily allowance of $10-12 \mathrm{mg}$ recommended by the Department of Health and Social Security (1979). Rats fed ad lib. will consume in the region of $20 \mathrm{~g} / \mathrm{d}$ of semi-synthetic diet containing the American Institute of Nutrition (1977) recommended concentration of $\mathrm{Fe}(35 \mathrm{mg} / \mathrm{kg})$. Thus, the daily intake of $\mathrm{Fe}$ is approximately $0.7 \mathrm{mg}$. It was considered, therefore, that an equivalent supplement range for rats would be $1 \cdot 4-7 \cdot 0$ $\mathrm{mg} \mathrm{Fe} / \mathrm{d}$. The mid-point of $4 \mathrm{mg}$ was chosen for the present study.

On the morning after the 7 th day of supplementation, all rats were given a low-Fe meal at 08.30 hours and killed between 09.30 and 15.00 hours. Blood samples and livers were taken and analysed as described previously for the ten animals killed at the beginning of the supplementation period.

\section{Statistical analysis}

Values for groups 1-7 were examined for variance homogeneity and, initially, subjected to a one-way analysis of variance. If this showed a significant treatment effect $(P<0.05)$, values for supplemented groups (groups $2-7$ ) were subject to a two-way analysis of variance to determine the effects of frequency of supplementation (every day, alternate days or every 3 rd day), type of dosing (single or multiple) and any frequency $\times$ dose interaction. Since all groups had an equal number of replicates (twelve), a pooled standard error of the mean (SEM) is given in the tables of results. The standard error of difference of the means (SED), with $66 \mathrm{df}$, is given to allow the significance of the difference between any pair of means to be calculated : $t=\left(\operatorname{mean}_{1}-\operatorname{mean}_{2}\right) /$ SED with $66 \mathrm{df}$. The least significant difference (LSD) is also tabulated for $P<0.05$. 
RESULTS

Analysis of blood and liver from the ten rats killed immediately before the supplementation period demonstrated the degree of anaemia produced by giving the low-Fe diet for $14 \mathrm{~d}$. Values obtained were as follows: RBC 4.78 (SE 0.17) $\times 10^{12} / 1$, PCV 0.261 (SE 0.009), MCV 53.4 (SE 0.3) fl, Hb 95.6 (SE 2.9) g/l, liver dry weight 1.68 (SE 0.03) g, total liver Fe 191 (SE 14) $\mu \mathrm{g}$. The values for $\mathrm{Hb}, \mathrm{PCV}$ and total liver Fe were approximately 23,35 and $78 \%$ respectively below values previously obtained for rats of a similar age fed on a diet containing the American Institute of Nutrition (1977) recommended concentration of $35 \mathrm{mg} \mathrm{Fe} / \mathrm{kg}$ (Southon et al. 1988).

With the exception of body-weight, supplementation (groups 2-7) had a significant effect $(P<0.001)$ on all measured variables when values were compared with the unsupplemented control group (group 1; Table 3).

\section{The effect of the various supplementation regimens on growth and Fe status}

Body-weight. There was no significant difference in body-weight between any of the groups.

Blood. RBC and PCV were unaffected by the frequency of supplementation but values for groups given the single supplement were slightly higher $(P<0.05)$ compared with those given a multiple dose. The type of supplement given did not significantly influence $\mathrm{MCV}$, but there appeared to be a very small decline in MCV $(P<0.05)$ with decreasing frequency of supplementation. The type or frequency of supplementation did not affect $\mathrm{Hb}$ concentration.

Liver. Liver dry weight and total liver Fe were unaffected by type or frequency of supplementation.

\section{DISCUSSION}

The rat has long been held as a valid model for man as it responds in a similar way to many dietary and physiological factors known to affect non-haem Fe absorption. Studies with non-anaemic rats have demonstrated that the retention of radio-labelled Fe from a test meal is inversely related to previous short-term (one meal) dietary Fe intake, and that the magnitude of the suppressive effect of a single high-Fe meal on subsequent absorption linearly decreases with time after consumption of the meal (Fairweather-Tait \& Wright, 1984; Fairweather-Tait et al. 1985). The estimated time for the effect to disappear was found to approximate to mucosal cell turnover time (Fairweather-Tait et al. 1985). This finding supports the hypothesis that there is a marked local effect of exposure to dietary $\mathrm{Fe}$ on the regulatory role of the mucosal epithelial cells on Fe absorption and more recent evidence suggests that regulation may be exercised mainly through suppression of mucosal uptake (Wright et al. 1989). The effect of previous Fe intake on absorption in man is less well documented but there is evidence that oral Fe doses in the same range as those given as routine supplements to pregnant women, and subjects with symptoms of Fe deficiency, also suppresses $\mathrm{Fe}$ absorption for at least $24 \mathrm{~h}$ after the dose (Solomons et al. 1983; Fairweather-Tait \& Minski, 1986; O’Neil-Cutting \& Crosby, 1987). It may be suggested, therefore, that routine daily oral supplementation with Fe may not be the most efficient and cost-effective way of maintaining Fe status during pregnancy, or improving status in cases where Fe deficiency has been identified. However, since the efficiency of Fe absorption is known to be significantly increased in Fe-deficient subjects (Heinrich et al. 1977) the degree of mucosal feed-back inhibition is likely to be less than in the non-anaemic state. In this case, daily supplementation may indeed be the best method for the rapid correction of $\mathrm{Fe}$ deficiency. However, little is known about the influence of different patterns of 
$\overbrace{}^{2}$

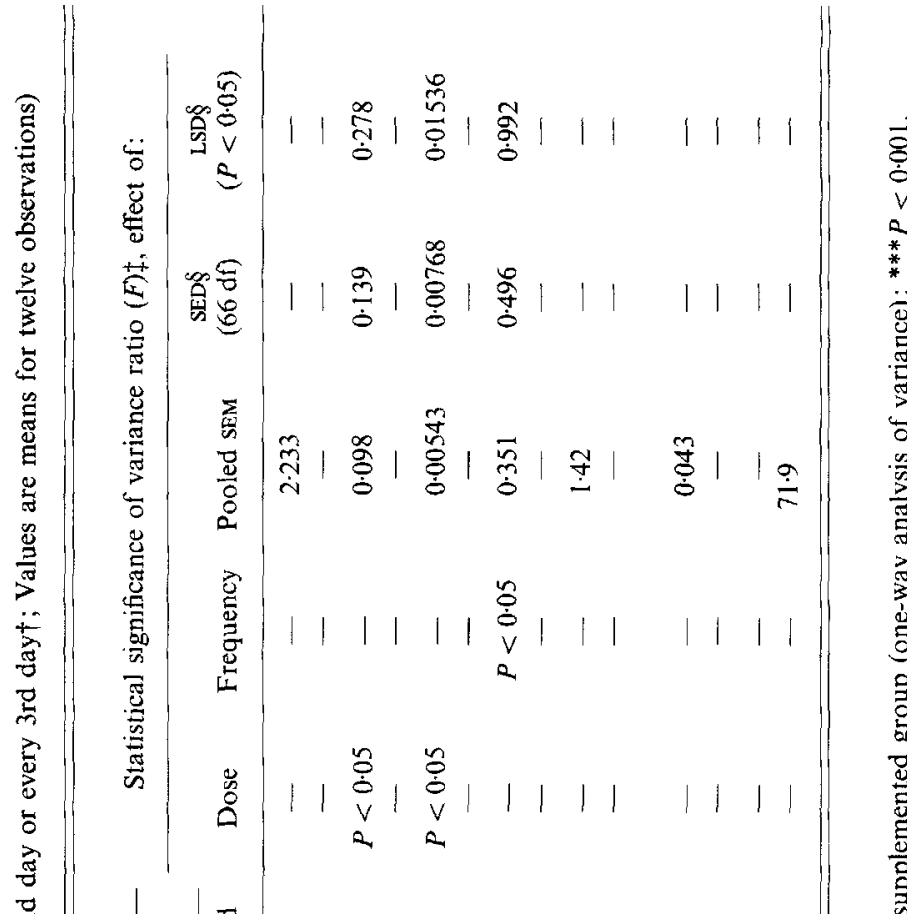

$\overrightarrow{8}$
$\dot{0}$
v
$*$
$*$
$*$

$\widetilde{8}$

ङ

ฐ

$S$

辛

$\frac{2}{8}$

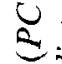

ह ะ

$\stackrel{5}{5}$

ฐ

2

造幽

$\therefore 5$

ชิ

है

芒

¿. एँ

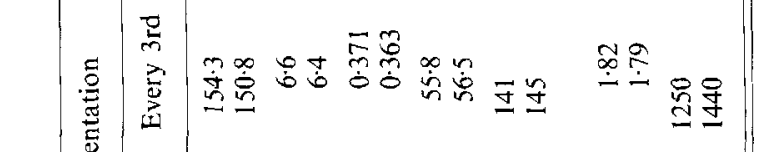

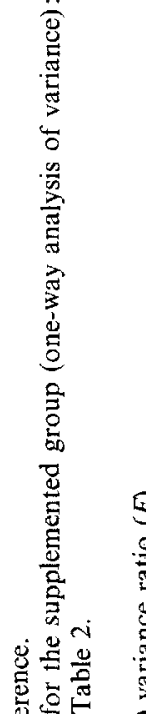

害恋

ㄴํㅇ

ड

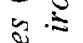

$\stackrel{\Xi}{\Xi}$

$\overline{2}$

80

ะิ

跤

농

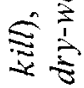

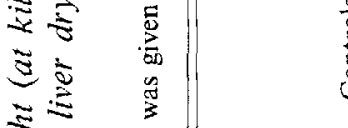

焉

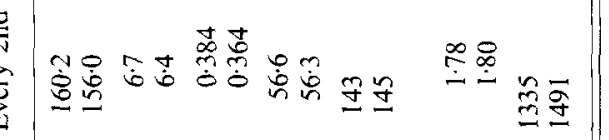

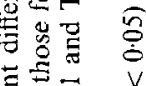

若

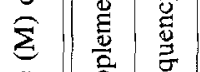

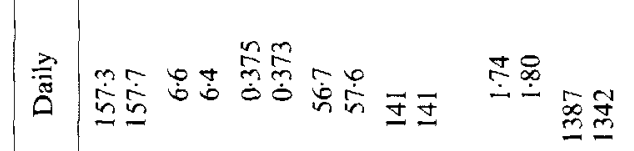

E 2

运

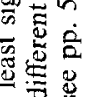

要

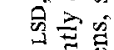

总节

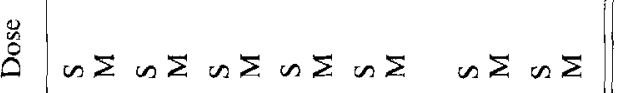

5

$\stackrel{5}{8}$

늘

萻

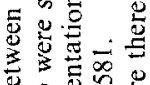

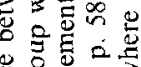

응

可解

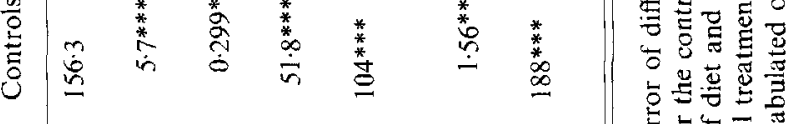

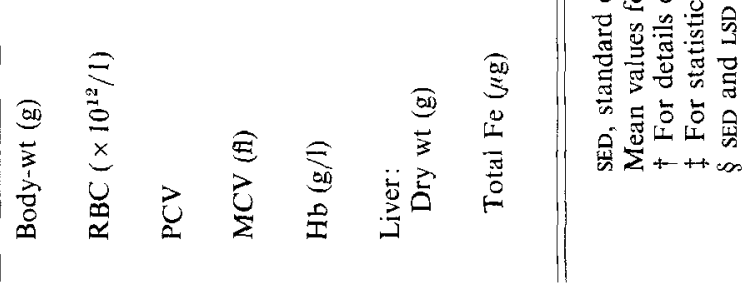


supplementation on subsequent $\mathrm{Fe}$ absorption and status in anaemic subjects. In the present study, the possibility that dosing every 2 nd or 3 rd day may be as effective as daily supplementation in improving the $\mathrm{Fe}$ status of anaemic rats was investigated. The possibility that daily multiple dosing may be a more effective means of Fe therapy than giving a single larger supplement was also considered, since the proportion of $\mathrm{Fe}$ absorbed from small doses has been shown to be greater than that from larger doses (Bothwell et al. 1979), and a smaller Fe dose may also diminish the sensitive feed-back inhibition on subsequent $\mathrm{Fe}$ absorption.

With respect to the influence of frequency of supplementation on the improvement of $\mathrm{Fe}$ status in anaemic rats, the results of the present study clearly demonstrated that there was little advantage in daily supplementation as opposed to supplementing every 3 rd day. The group of rats which received a supplement of $4 \mathrm{mg} \mathrm{Fe}$ every 3 rd day, the total supplement over the experimental period being $12 \mathrm{mg}$, had a similar RBC, PCV, Hb concentration and total liver $\mathrm{Fe}$ at the end of the experimental period to those receiving a daily $4 \mathrm{mg}$ supplement, a total supplement of $28 \mathrm{mg}$. Comparison of the Fe status of rats at the end of an experimental period, however, is not the only consideration, since the rapidity with which Fe-deficiency anaemia is corrected is also important. For this reason a relatively short experimental period of $7 \mathrm{~d}$ was chosen in the present study so that any major differences in the rate of improvement between groups could be detected. The only significant difference observed was an apparently slower recovery in $\mathrm{MCV}$ in rats supplemented less frequently, but the difference in mean values between rats supplemented daily and those supplemented every 3 rd day was less than $2 \%$. The fact that PCV values for all supplemented groups were approximately $10 \%$ below expected values for Fe-replete rats of this age (PCV values in Fe replete Wistar rats 0.40-0.43 (Southon et al. 1988; Fairweather-Tait \& Southon, 1989)) indicates that supplemented animals had not fully recovered by the end of the experimental period. This suggests that the rate of recovery was unaffected by the different supplementation regimens.

Although less frequent supplementation did not result in any improvement in Fe status in the anaemic rats, over and above that observed in those given the daily supplement, other implications of this type of supplementation regimen need to be considered in relation to the administration of Fe supplements to human subjects. First, lower amounts of supplemental Fe would minimize unpleasant side-effects such as constipation, diarrhoea, nausea and epigastric pain which can often result in non-compliance with Fe therapy (Solvell, 1970). Second, the risk of adverse interactive effects of Fe on the absorption of other essential minerals, particularly zinc, would be reduced (Solomons, 1986; Southon et al. 1989). Finally, it should be possible to cut the cost of Fe therapy programmes considerably.

Administration of the $4 \mathrm{mg}$ supplement as a multiple, rather than a single, dose did not significantly improve recovery. Total liver Fe values were slightly higher in the groups given a multiple supplement every 2 nd or 3 rd day, compared with their single-supplement counterparts, but the differences were not significant. On the other hand, RBC and PCV were significantly lower, overall, in groups receiving the multiple supplement than in those given the single supplement, although differences between means were only $2-3 \%$. The hypothesis that providing the supplement in smaller doses throughout the day may increase the proportion of Fe absorbed, therefore, was not confirmed. In any event, a regimen which required the administration of three doses of a supplement in any $1 \mathrm{~d}$, rather than a single supplement, is likely to reduce compliance to the therapy.

In conclusion, the results of the present study demonstrated that anaemic rats given an Fe supplement every 3rd day, over $7 \mathrm{~d}$, achieved a similar Fe status at the end of this period to rats given $133 \%$ more supplemental $\mathrm{Fe}$ as a daily supplement. In view of the important 
advantages offered by reducing the amount of Fe prescribed for the correction of $\mathrm{Fe}$ deficiency anaemia in man, the effectiveness of such a regimen should be investigated in human subjects.

\section{REFERENCES}

American Institute of Nutrition (1977). Report of the American Institute of Nutrition ad hoc committee on standards for nutritional studies. Journal of Nutrition 107, 1340-1348.

Bothwell, T. H., Charlton, R. W., Cook, J. D. \& Finch, C. A. (1979). Iron Metabolism in Man, pp. $261-262$. Oxford: Blackwell Scientific Publications.

Department of Health and Social Security (1979). Recommended daily amounts of food energy and nutrients for groups of people in the United Kingdom. Report on Health and Social Subjects no. 15. London: H.M. Stationery Office.

Fairweather-Tait, S. J. (1986). Iron availability - the implications of short-term regulation. Nutrition Bulletin 11, $174-180$

Fairweather-Tait, S. J. \& Minski, M. J. (1986). Studies on iron availability in man, using stable isotope techniques. British Journal of Nutrition 55, 279-285.

Fairweather-Tait, S. J. \& Southon, S. (1989). Studies of iron:zinc interactions in adult rats and the effect of iron fortification of two commercial infant weaning products on iron and zinc status of weanling rats. Journal of Nutrition 119, 599-606.

Fairweather-Tait, S. J., Swindell, T. E. \& Wright, A. J. A. (1985). Further studies in rats on the influence of previous iron intake on the estimation of bioavailability of Fe. British Journal of Nutrition 54, $79-86$.

Fairweather-Tait, S. J. \& Wright, A. J. A. (1984). The influence of previous intake on the estimation of bioavailability of iron from a test meal given to rats. British Journal of Nutrition 51, 185-191.

Heinrich, H. C., Bruggemann, J., Gabbe, E. E. \& Glaser, M. (1977). Correlation between diagnostic ${ }^{59} \mathrm{Fe}-$ absorption and serum ferritin concentration in man. Zeitschrift Fur Naturforshung 32C, 1023-1025.

O'Neill-Cutting, M. A. \& Crosby, W. H. (1987). Blocking of iron absorption by a preliminary oral dose of iron. Archives of Internal Medicine 147, 489-491.

Solomons, N. W. (1986). Competitive interaction of iron and zinc in the diet: consequences for human nutrition. Journal of Nutrition 116, 927-935.

Solomons, N. W., Pineda, O., Viteri, F. \& Sandstead, H. H. (1983). Studies on the bioavailability of zinc in human: mechanism of the intestinal interaction on non-heme Fe and zinc. Journal of Nutrition 113, 337.349.

Solvell, L. (1970). Oral iron therapy-side effects. In Iron Deficiency: Pathogenesis, Clinical Aspects, Therapy, pp. 573-583 [L. Hallberg, H.-G. Harwerth and A. Vannotti, editors]. London: Academic Press.

Southon, S., Johnson, I. T., Gee, J. M. \& Price, K. R. (1988). The effect of gypsophila saponins in the diet on mineral status and plasma cholesterol concentration in the rat. British Journal of Nutrition 59, 49-55.

Southon, S., Wright, A. J. A. \& Fairweather-Tait, S. J. (1989). The effect of combined dietary iron, calcium and folic acid supplementation on apparent ${ }^{65} \mathrm{Zn}$ absorption and $\mathrm{Zn}$ status in pregnant rats. British Journal of Nutrition 62, 415-423.

Wright, A. J. A., Southon, S. \& Fairweather-Tait, S. J. (1989). Measurement of non-haem-iron absorption in nonanaemic rats using ${ }^{59} \mathrm{Fe}$ : can the $\mathrm{Fe}$ content of duodenal mucosal cells cause lumen or mucosal radioisotope dilution, or both, thus resulting in the underestimation of Fe absorption? British Journal of Nutrition 62 , $719-727$ 